\title{
Morphology of water-based chemical solution deposition (CSD) lead titanate films on different substrates: Towards island formation
}

\author{
C. De Dobbelaere ${ }^{a}$, A. Hardy ${ }^{\text {a,b,c }}$, J. D'Haen ${ }^{\text {b,d }}$, H. Van den Rul ${ }^{\text {a,b }}$, \\ M.K. Van Bael ${ }^{\mathrm{a}, \mathrm{b}, *}, \mathrm{~J}_{\text {. Mullens }}{ }^{\mathrm{a}}$ \\ ${ }^{a}$ Hasselt University, Institute for Materials Research, Inorganic and Physical Chemistry, Agoralaan - Building D, B-3590 Diepenbeek, Belgium \\ ${ }^{\mathrm{b}}$ IMEC vzw, Division IMOMEC, Agoralaan - Building D, B-3590 Diepenbeek, Belgium \\ ${ }^{\mathrm{c}}$ XIOS Hogeschool Limburg, Department IWT, Agoralaan - Building H, B-3590 Diepenbeek, Belgium \\ ${ }^{\mathrm{d}}$ Hasselt University, Institute for Materials Research, Materials Physics, Wetenschapspark 1, B-3590 Diepenbeek, Belgium
}

Received 28 July 2008; received in revised form 19 September 2008; accepted 9 October 2008

Available online 2 December 2008

\begin{abstract}
This study aims at the deposition of $\mathrm{PbTiO}_{3}$ (PT) islands prepared by a water-based chemical solution deposition (CSD). Two aqueous citrato-based $\mathrm{PbTiO}_{3}$ precursor solutions, either with or without peroxide, are deposited by spin coating. The effect of different substrates on the formation of separated grains or islands is examined. It is observed that spin coating of a $0.6 \mathrm{M}$ precursor solution on a $\mathrm{Pt}(111) / \mathrm{IrO}_{2} / \mathrm{Ir} / \mathrm{SiO}_{2} / \mathrm{Si}$ substrate gives the best results towards island formation. For this substrate, crystallizations are carried out between $600{ }^{\circ} \mathrm{C}$ and $900{ }^{\circ} \mathrm{C}$. A final crystallization at $800^{\circ} \mathrm{C}$ results in the highest degree of separation for the islands, while keeping the platinized substrate intact. The deposition of diluted precursors shows that it is possible to form islands from a precursor solution with a concentration down to $0.3 \mathrm{M}$. Solutions with a lower concentration result in irregularly shaped structures.
\end{abstract}

(C) 2008 Elsevier Ltd. All rights reserved.

Keywords: Sol-gel processes; Films; Electron microscopy; Microstructure-final; Aqueous precursor

\section{Introduction}

Lead titanate has received a lot of attention in the last decades because of dielectric, pyroelectric, piezoelectric and ferroelectric properties, which emerge from its tetragonal perovskite structure at room temperature. Research on $\mathrm{PbTiO}_{3}(\mathrm{PT})$ bulk ceramics ${ }^{1-3}$ and thin films, resulted in the use of PT in several electronic applications, such as infrared sensors, microactuators, capacitors, electro-optic devices and non-volatile ferroelectric random access memories (NVFeRAMs). ${ }^{4-7}$

Thin films of PT have been deposited on several substrates by different deposition techniques, such as pulsed laser deposition

\footnotetext{
* Corresponding author at: Hasselt University, Institute for Materials Research, Inorganic and Physical Chemistry, Agoralaan - Building D, B-3590 Diepenbeek, Belgium. Tel.: +32 112683 07; fax: +32 11268301 .

E-mail addresses: christopher.dedobbelaere@uhasselt.be

(C. De Dobbelaere), an.hardy@uhasselt.be (A. Hardy), jan.dhaen@uhasselt.be (J. D’Haen), heidi.vandenrul@uhasselt.be (H. Van den Rul),

marlies.vanbael@uhasselt.be (M.K.Van Bael),jules.mullens@uhasselt.be (J. Mullens).
}

(PLD), ${ }^{8}$ molecular-beam epitaxy (MBE), ${ }^{9}$ sputter deposition ${ }^{10}$ and chemical vapour deposition (CVD). ${ }^{11,12}$ Chemical solution deposition (CSD) methods combined with chemical routes such as sol-gel, ${ }^{13}$ hybrid and metallo-organic decomposition $(\mathrm{MOD})^{14}$ are advantageous because of their simplicity, stoichiometric control and relatively low investment costs. ${ }^{15}$

The demand for ultra-high-density memories ${ }^{16,17}$ stimulates current research of top-down (lithography-based) and bottom-up (self-assembly based) approaches towards the fabrication of regular arrays of ferroelectric nanostructures. Top-down approaches can result in a good spatial resolution and precision but are expensive, time-consuming and not well suited to result in $<100 \mathrm{~nm}$ patterns. Bottom-up techniques on the other hand, allow the fabrication of (nano)structures but the realization of an organized arrangement of the structures is still a challenge. ${ }^{18}$ However, Lee et al. recently fabricated well-ordered nanocapacitors (64 $\mathrm{nm}$ in size) in a completely bottom-up approach using PLD in combination with ultrathin AAO (anodic aluminium oxide) masks. ${ }^{19}$ Other approaches have also been studied, but no perfect arrangement of the nanostructures could be obtained 
so far. Among them are the high temperature instability of thin films ${ }^{20}$ and the use of micro-emulsions ${ }^{21}$ or diblockcopolymers. ${ }^{22}$ A combination of top-down and bottom-up can also result in well-defined organized nanostructures. Clemens et al. for example used electron-beam lithography generated $\mathrm{TiO}_{2}$ templates as seeds for the formation of PT nanostructures, ${ }^{23}$ followed by the deposition of the ferroelectric material by chemical solution deposition, a powerful bottom-up technique. ${ }^{15}$

During the last several years, our laboratory has gathered a considerable know-how on the synthesis of totally water-based precursor solutions for the preparation of numerous (multi)metal oxides as powders or as thin films. ${ }^{24-29}$ In this aqueous precursor route, metal salts or metallo-organics are dissolved in water only (no other solvent is used to improve the solubility) and stabilized against hydrolysis and condensation using, e.g. peroxo and/or citrato ligands as complexing agents. The stable solutions can be stored in simple glassware and need no special treatments during further manipulations, such as the protection from ambient moisture. Also, the use of a non-hazardous and inexpensive solvent is of economical interest and ecological importance. Because of these advantages and their flexibility, aqueous precursors were recently used for e.g. fast material screening purposes for alternative gate-dielectric materials. ${ }^{30}$ Other aqueous precursors for PT (not citrato(peroxo)-based) have already been used to prepare PT powders ${ }^{3}$ or films by hydrothermal synthesis, ${ }^{31}$ but to our knowledge not for CSD purposes.

In the present work, two water-based precursor solutions for the deposition of $\mathrm{PbTiO}_{3}$ are presented and compared for the first time. After comparison of the two precursors, the deposition of the material is further examined. This study is initiated by comparing the morphology and crystallinity on different substrates. After selecting the substrate most promising towards island formation, series of diluted precursors are deposited and several crystallization temperatures are compared, aiming at the formation of PT islands. The presented study contributes to a better understanding of the formation of islands on different substrates and provides experimental information needed to gain further fundamental insights in this field.

\section{Experimental}

\subsection{Starting materials and reagents}

Starting materials for the synthesis of the PT precursor solutions are liquid $\mathrm{Ti}(\mathrm{IV})$-isopropoxide $\left(\left[\left(\mathrm{CH}_{3}\right)_{2} \mathrm{CHO}\right]_{4} \mathrm{Ti}\right.$, Acros Organics, $98+\%)$, lead citrate trihydrate $\left(\mathrm{Pb}_{3}\left(\mathrm{C}_{6} \mathrm{H}_{5} \mathrm{O}_{7}\right)_{2} \cdot 3 \mathrm{H}_{2} \mathrm{O}\right.$, Alfa Aesar, 99\%), citric acid $\left(\mathrm{C}_{6} \mathrm{H}_{8} \mathrm{O}_{7}\right.$, Sigma-Aldrich, $\left.99 \%\right)$, hydrogen peroxide $\left(\mathrm{H}_{2} \mathrm{O}_{2}\right.$, Acros Organics, $35 \mathrm{wt} . \%$ in $\mathrm{H}_{2} \mathrm{O}$, stabilized, p.a.) and ammonia $\left(\mathrm{NH}_{3}\right.$, Merck, $32 \%$ in $\mathrm{H}_{2} \mathrm{O}$, extra pure). $\mathrm{HNO}_{3}$ (J.T. Baker, 69-70\%, Baker Instra-analyzed ${ }^{\circledR}$ Reagent) is used in the sample preparation for ICP-AES (Inductively Coupled Plasma-Atomic Emission Spectroscopy) analysis. The solvent for the precursor preparation is pure milli$\mathrm{Q}$ water with a resistivity of $18 \mathrm{M} \Omega \mathrm{cm}$.

Polished $\mathrm{SrTiO}_{3}$ substrates are obtained from CrysTec $\mathrm{GmbH}$ (Berlin, Germany). The $\operatorname{Pt}\left(\begin{array}{lll}1 & 1 & 1\end{array}\right) / \mathrm{IrO}_{2} / \mathrm{Ir} / \mathrm{SiO}_{2} / \mathrm{Si}$ as well as the $\mathrm{SiO}_{2} / \mathrm{Si}$ substrates are provided by IMEC (Leuven, Belgium).

\subsection{Methods and apparatus}

The metal ion concentration of the different monometal precursors is determined by means of ICP-AES (PerkinElmer Optima 3000 DV). The crystallographic phase and orientation of the deposited films is studied at room temperature by X-ray diffraction (XRD) on a Siemens D-5000 diffractometer with $\mathrm{Cu} \mathrm{K} \mathrm{K}_{\alpha 1}$ radiation operating in $\theta-2 \theta$ mode. To investigate the surface morphology, scanning electron micrographs (SEM) of the deposited layers are obtained on a FEI Quanta 200FEG SEM equipped with secondary electron (SE) and backscattered electron (BSE) detectors. Chemical analysis is performed by energy-dispersive X-ray spectroscopy (EDX) with a $\mathrm{Si}(\mathrm{Li})$ detector with Bruker software. The $\mathrm{pH}$ of the precursor solutions is measured with a Schott Geräte pH-Electrode BlueLine Type $18 \mathrm{pH}$.

Local piezoelectric activity is measured by piezoresponse force microscopy (PFM), used in combination with a commercial scanning force microscope (SFM) $\left(\right.$ Nanotec $^{\circledR}$ Electrónica with $\mathrm{WSxM}^{\circledR}$ software), by inducing piezoelectric vibrations in the structures under increasing and decreasing (DC) voltage, measuring when the field is driven back to zero (remanent or pulse hysteresis loops). ${ }^{32}$

\subsection{Synthesis of the precursor solutions}

Two different titanium(IV) precursors with metal ion concentrations of $\sim 0.7 \mathrm{M}$ are synthesized based on the methods described in Refs. [33,34]. Liquid Ti(IV)-isopropoxide ( $22 \mathrm{~mL})$ is hydrolyzed in $300 \mathrm{~mL}$ water, leading to the formation of a hydrolysis product that is filtered, washed several times with water and mixed with citric acid in a 2:1 molar ratio against Ti(IV). For the $\mathrm{H}_{2} \mathrm{O}_{2}$-based precursor (A), $\mathrm{H}_{2} \mathrm{O}_{2}$ is added in a 1.2:1 ratio against $\mathrm{Ti}(\mathrm{IV})$, whereas for the $\mathrm{H}_{2} \mathrm{O}_{2}$-free solution (B), just enough $\mathrm{H}_{2} \mathrm{O}$ is added to disperse the powder (approx. $15 \mathrm{~mL} / 0.7 \mathrm{M} \mathrm{Ti}(\mathrm{IV}))$. Solutions A and $\mathrm{B}$ are refluxed in air at $80^{\circ} \mathrm{C}$ for respectively $2 \mathrm{~h}$ and $4 \mathrm{~h}$. After reflux, the $\mathrm{pH}$ of both warm solutions is adjusted to $\sim 6.8$ using ammonia. This is accompanied by a further increase of the solutions' temperature due to exothermic reactions. After cooling the solutions to room temperature, the $\mathrm{pH}$ is finally set to 7.0. Dilution of the solutions, results in two precursors having a titanium ion concentration of $\sim 0.7 \mathrm{M}$ and a pH of $\sim 7.0$.

A $\sim 0.7 \mathrm{M}$ lead precursor solution is obtained by combining lead citrate trihydrate and citric acid in water, ensuring a 2:1 ratio of citric acid against $\mathrm{Pb}$ (II). After subsequent reflux in air at $80^{\circ} \mathrm{C}$ for $2 \mathrm{~h}$, the $\mathrm{pH}$ of the obtained dispersion is increased to $\sim 8.6$ with ammonia to dissolve the lead citrate precipitate. A clear and colourless solution is obtained this way. The lead(II) precursor is immediately used after synthesis because of its limited stability of a few weeks to 1 month.

A lead titanate precursor with a total metal ion concentration of $0.6 \mathrm{M}$ is prepared by mixing both monometal ion precursors in the right molar ratio. The combined precursor solution with $\mathrm{pH}$ $\sim 8.0$ is further diluted with water to obtain the desired concentrations of $0.3 \mathrm{M}, 0.12 \mathrm{M}, 0.06 \mathrm{M}$ and $0.03 \mathrm{M}$. Sets of solutions 

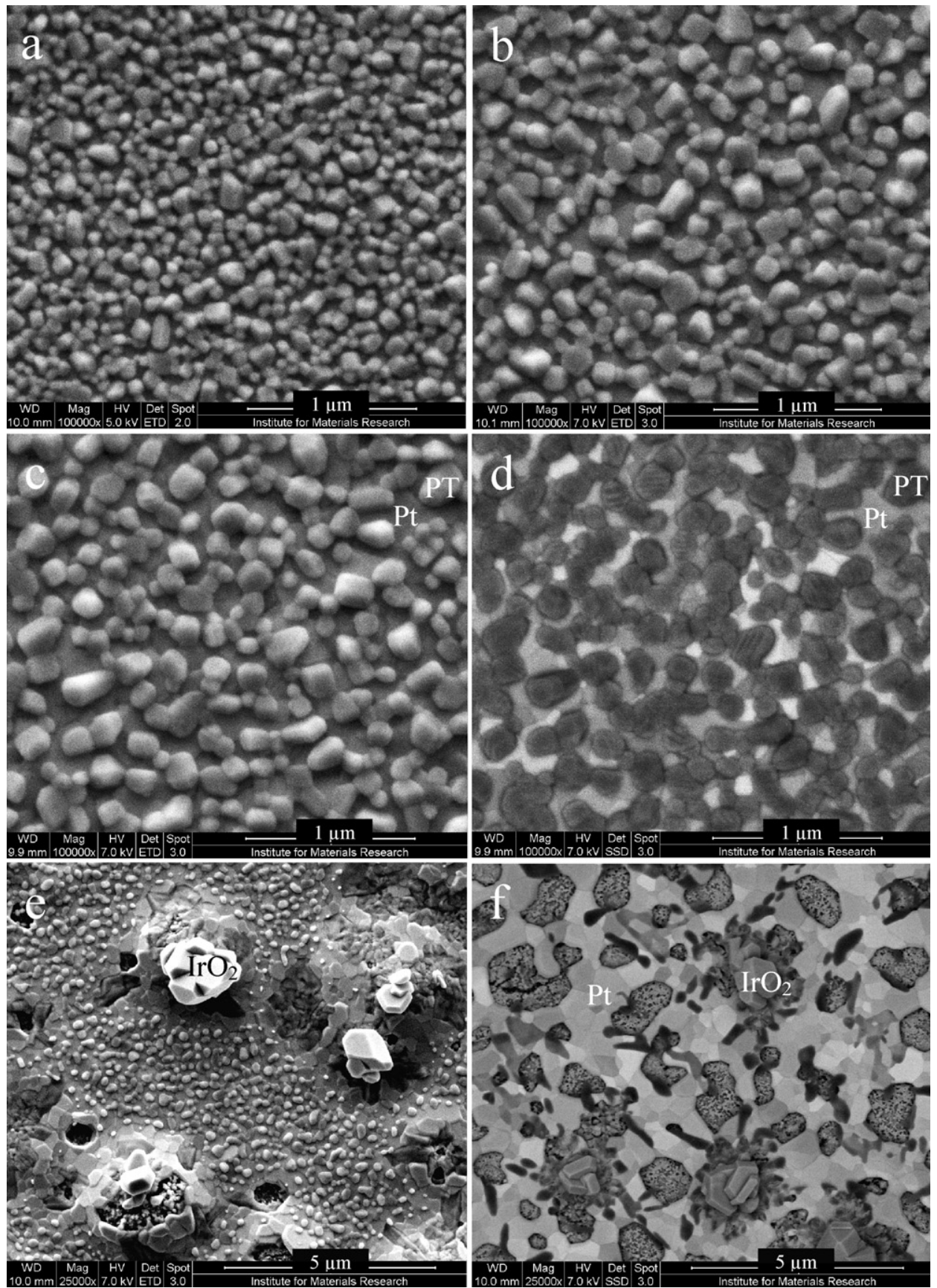

Fig. 1. Plane-view SE (back scattered, BSE) images obtained for the deposition of PT precursor solution A with a total metal ion concentration of $0.6 \mathrm{M}$ on $\mathrm{Pt}(111) / \mathrm{IrO}_{2} / \mathrm{Ir} / \mathrm{SiO}_{2} / \mathrm{Si}$. The final crystallization temperature is (a) $700^{\circ} \mathrm{C}$, (b) $750{ }^{\circ} \mathrm{C}$, (c) $800^{\circ} \mathrm{C}$, (d) $800^{\circ} \mathrm{C}$ (BSE), (e) $850^{\circ} \mathrm{C}$ and (f) $900{ }^{\circ} \mathrm{C}$ (BSE).

either with (A) or without $\mathrm{H}_{2} \mathrm{O}_{2}$ (B) in the titanium(IV) precursor are prepared. All of the prepared solutions contain a $16 \mathrm{~mol} \%$ excess of $\mathrm{Pb}^{2+}$ to compensate for the lead losses during thermal treatment. $^{35,36}$

\subsection{Deposition of PT}

The substrates are first treated by a sulphuric acid hydrogen peroxide mixture (SPM) and an ammonia hydrogen peroxide mixture (APM) ${ }^{37}$ resulting in a clean, hydrophilic substrate surface with a very high wettability towards water-based solutions. Before deposition on these substrates, the precursors are filtered with a $0.2 \mu \mathrm{m}$ syringe filter to remove dust. Single layered PT films are fabricated from both peroxide containing (A) and peroxide free (B) precursors by spin coating (30 s, $3000 \mathrm{rpm}$ with an acceleration of $1000 \mathrm{rpm} / \mathrm{s}$ ). The macroscopically uniform, as deposited films, are dried and pyrolyzed on hot plates in ambient air at the following temperatures/times: $200^{\circ} \mathrm{C} / 2^{\prime}, 350^{\circ} \mathrm{C} / 2^{\prime}$ and $450{ }^{\circ} \mathrm{C} / 2^{\prime}$. The final crystallizations between $700^{\circ} \mathrm{C}$ and $900^{\circ} \mathrm{C}$ $\left(30^{\prime}\right)$ are carried out in a preheated crucible in a tube furnace $\left(0.5 \mathrm{~L} / \mathrm{min}\right.$ flow of dry air). The final crystallization at $600^{\circ} \mathrm{C}$ $\left(30^{\prime}\right)$ is carried out on a hot plate in ambient air with the lid of the hot plate closed to maintain the temperature. In both cases, the substrates are cooled abruptly to room temperature after the 

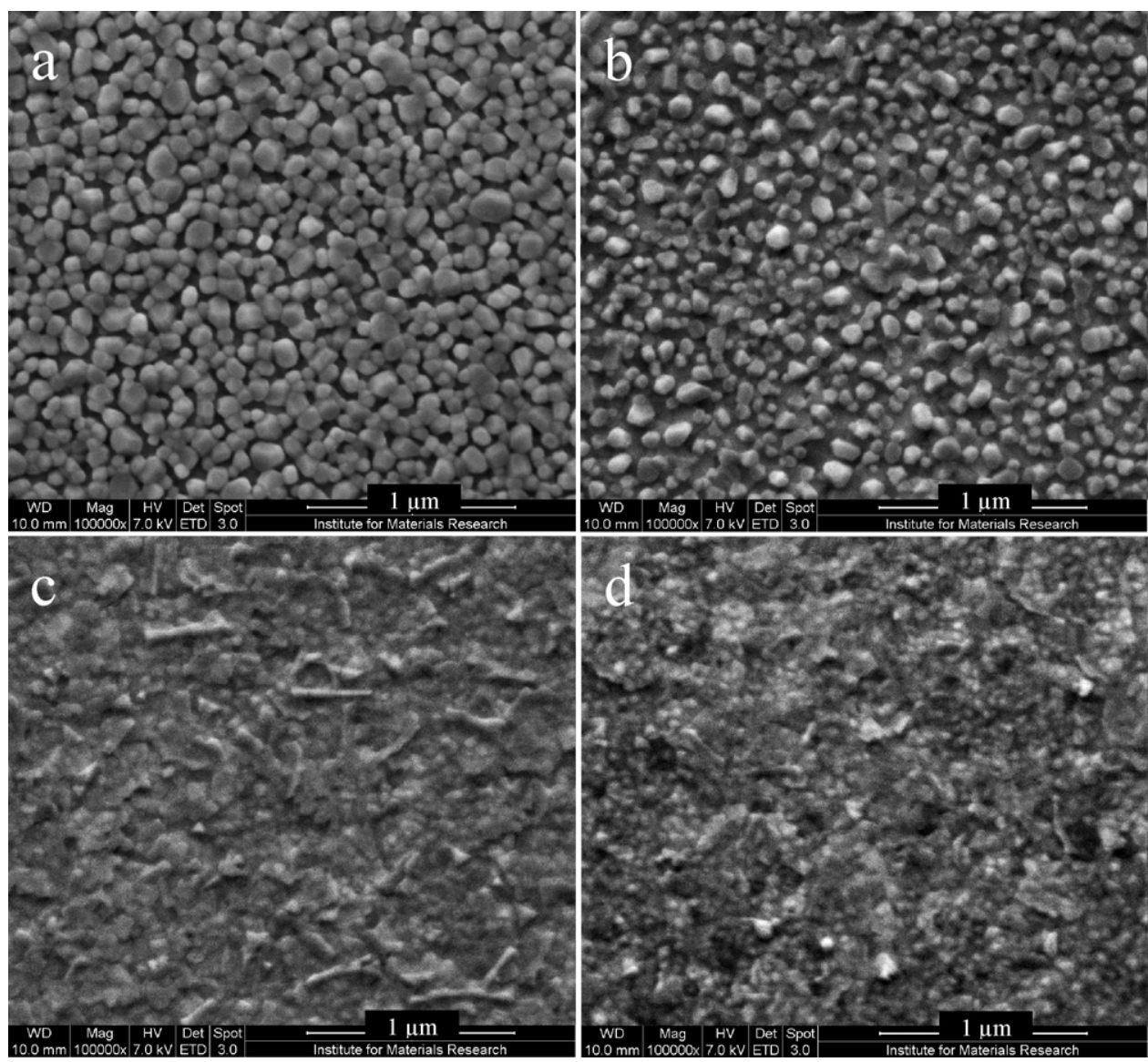

Fig. 2. Plane-view SE images obtained for the deposition of PT precursor solution B with different total metal ion concentrations. The deposition is carried out on $\mathrm{Pt}\left(11\right.$ ) $/ / \mathrm{IrO}_{2} / \mathrm{Ir} / \mathrm{SiO}_{2} / \mathrm{Si}$ with a crystallization temperature of $700^{\circ} \mathrm{C}$. (a) $0.6 \mathrm{M}$, (b) $0.3 \mathrm{M}$, (c) $0.12 \mathrm{M}$ and (d) $0.06 \mathrm{M}$.

thermal treatment is finished, except for the $\mathrm{SrTiO}_{3}$ substrates, which are cooled slowly to avoid breaking.

\section{Results and discussion}

\subsection{Precursor systems}

Besides carboxylato ligands, peroxo ligands are frequently used as electron donating groups to stabilize highly valent metal ions against hydrolysis. ${ }^{36,38}$ The tetravalent titanium ion has the possibility to form stable water-soluble citrato complexes with ${ }^{34}$ or without ${ }^{39}$ peroxo ligands.

Malic et al. showed that the precursor type has a big influence on the microstructure of $\mathrm{PbTiO}_{3}$ films. ${ }^{40}$ As they reported, variations in precursor structure affects the pyrolysis behaviour, thickness and microstructure of the obtained PT films. It is believed that in the case of citrato (peroxo) titanium complexes, the extra oxygen present in the peroxo complex could have its repercussions on the phase and morphology of the deposited films since the intrinsic presence of more oxygen could facilitate phase formation. In order to study this effect, a titanium precursor with and without peroxo ligands is synthesized.

After reflux of the peroxide containing titanium(IV) precursor (A), an acid ( $\mathrm{pH} 1$ ), burgundy coloured solution is obtained. The solutions' colour proves the presence of 1:1 tita-
nium(IV):peroxo complexes. ${ }^{41,42}$ During the following addition of ammonia, this burgundy solution slowly changes its colour and becomes yellow-orange at $\mathrm{pH}$ 7. For the peroxo free solution (B) on the other hand, a colourless solution is obtained at all stages of the synthesis. This colour difference confirms that two different titanium complexes are synthesized.

Figs. 1(a) and 2(a) show SEM images of PT depositions on $\mathrm{Pt} / \mathrm{IrO}_{2} / \mathrm{Ir} / \mathrm{SiO}_{2} / \mathrm{Si}$ obtained from a $0.6 \mathrm{M}$ solution of PT precursor A and precursor B, respectively. No significant differences can be found in grain size, shape or intergrain distance.

As confirmed by comparing more depositions of both precursor systems on different substrates and with different process conditions, the use of a peroxo containing (A) or a peroxo (B) free PT precursor results in the same morphology and crystal phase (not shown). This means that during the further course of this study, precursor A and B can be interchanged without affecting the final morphology or crystal phase of the deposited material.

\subsection{Effect of substrate and temperature}

PT precursor A with a total metal ion concentration of $0.6 \mathrm{M}$ is spin coated onto different substrates: $\mathrm{Pt}\left(\begin{array}{lll}1 & 1 & 1\end{array}\right) / \mathrm{IrO} \mathrm{I}_{2} / \mathrm{Ir} / \mathrm{SiO}_{2} / \mathrm{Si}$, $\mathrm{SiO}_{2}(1.2 \mathrm{~nm}) / \mathrm{Si}$ and $\left(\begin{array}{lll}0 & 0 & 1\end{array}\right) \mathrm{SrTiO}_{3}$. After the drying and the pyrolysis steps, the film is crystallized at $600{ }^{\circ} \mathrm{C}$ or $700^{\circ} \mathrm{C}$. 

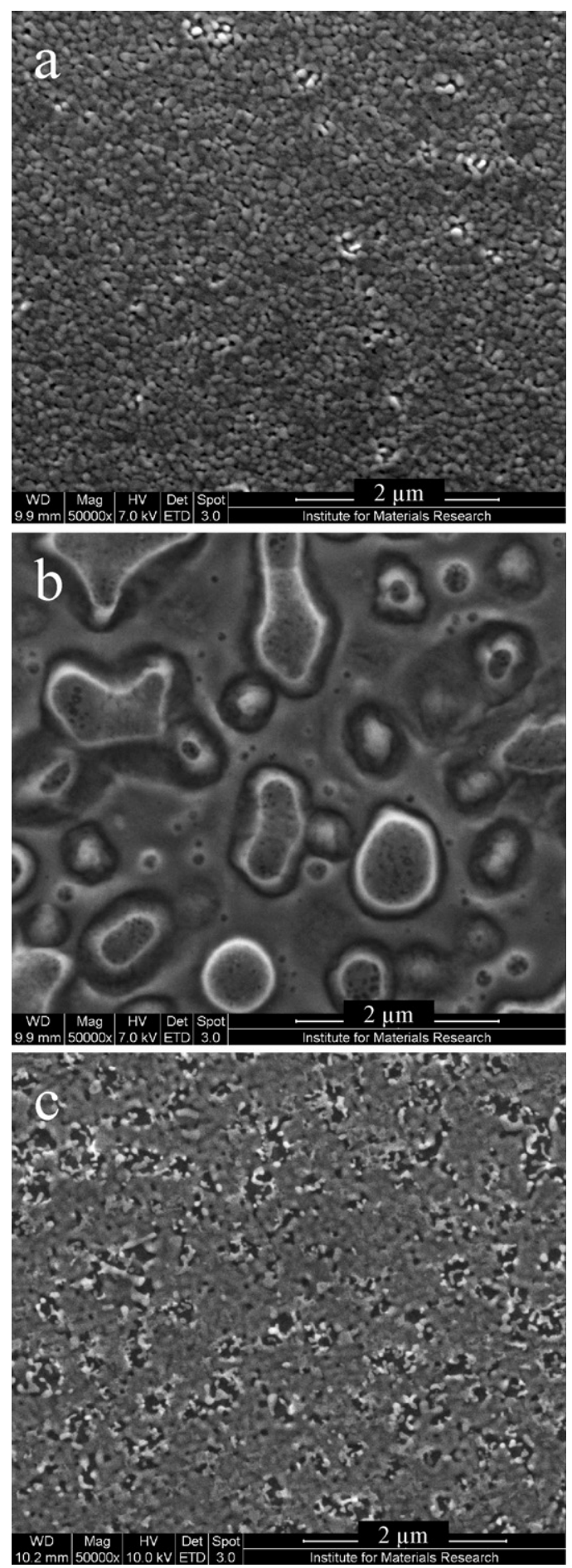

Fig. 3. Plane-view SE images obtained for the deposition of PT precursor solution A with a total metal ion concentration of $0.6 \mathrm{M}$ onto different substrates. The final crystallization temperature is $600{ }^{\circ} \mathrm{C}$. (a) $\mathrm{Pt}\left(\begin{array}{lll}1 & 1 & 1\end{array}\right) / \mathrm{IrO}_{2} / \mathrm{Ir} / \mathrm{SiO}_{2} / \mathrm{Si}$, (b)

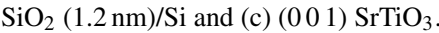

Fig. 3 shows the morphology on the different substrates after crystallization at $600^{\circ} \mathrm{C}$. As can be seen, the morphology is greatly influenced by the substrate. The platinized substrate gives rise to a polycrystalline layer (XRD, see below) with a uniform but non-continuous coverage of individual grains with lateral sizes between $50 \mathrm{~nm}$ and $160 \mathrm{~nm}$, Fig. 3(a). On the $\mathrm{SiO}_{2} / \mathrm{Si}$ substrate on the other hand, a continuous layer with hills or craters on its surface is formed and no individual grains can be discerned. These hills and craters could originate from the fact that there is no lattice matching between the amorphous $\mathrm{SiO}_{2}$ substrate and the potential PT lattice. The substrate is not beneficial to the nucleation of PT grains. Instead, homogeneous nucleation occurs in the film or at the interface of the film with the environment (free surface nucleation). Gases released during the treatment of the as deposited film, typically $\mathrm{CO}_{2}, \mathrm{NH}_{3}$ and $\mathrm{H}_{2} \mathrm{O},{ }^{43}$ can then be trapped under a solid layer of material, i.e. the hills, but can also be released resulting in the craters. This might be minimized by adjusting the pyrolysis steps in such a way that the release of gases occurs in a more controlled way. Finally, deposition on a single crystal strontium titanate substrate leads to a porous film.

Fig. 4 shows the morphology for the same set of substrates crystallized at $700^{\circ} \mathrm{C}$. The PT grains on the platinized substrate, Fig. 4(a), have lateral sizes between $70 \mathrm{~nm}$ and $140 \mathrm{~nm}$ and are more distant from each other than after crystallization at $600^{\circ} \mathrm{C}$. Thermal treatment after spin coating on the oxidized silicon wafers, Fig. 4(b), results in the formation of small grains and platelet-like structures. This obtained morphology can be attributed to phase segregation occurring at this elevated temperature, resulting in small structures on top of the continuous film. As indicated by the X-ray diffraction pattern in Fig. 5(e), these structures can be linked to the formation of a $\mathrm{Pb}_{2} \mathrm{O}_{3}$ phase. Hills or craters as in Fig. 3(b) are not observed anymore. Deposition on $\mathrm{SrTiO}_{3}$ and a final treatment at $700{ }^{\circ} \mathrm{C}$ results in a slightly porous but continuous coverage of the substrate, Fig. 4(c).

X-ray diffraction data of the layer deposited on

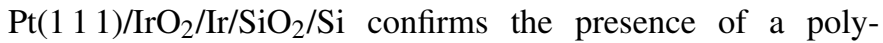
crystalline material for both temperatures (Fig. 5(a) and (d)). The diffraction peaks can be compared with the reference powder diffraction pattern for PT (JCPDS 06-0452) and show that the tetragonal phase of $\mathrm{PbTiO}_{3}$ is formed. For all $\mathrm{SiO}_{2} / \mathrm{Si}$ substrates however, no crystalline PT phase can be found. Fig. 5(b) and (e) shows the experimental XRD patterns for a deposition on $\mathrm{SiO}_{2}(1.2 \mathrm{~nm}) / \mathrm{Si}$ after crystallization at $600{ }^{\circ} \mathrm{C}$ and $700^{\circ} \mathrm{C}$, respectively. The only pattern that can be matched with the recorded pattern in the case of $700^{\circ} \mathrm{C}$ is that of $\mathrm{Pb}_{2} \mathrm{O}_{3}$ (JCPDS 36-0725). Kushida et al. ${ }^{44}$ reported for a six-layered PT film a better crystallization on $\mathrm{Pt} / \mathrm{Si}$ wafers than on fused quartz. Fused quartz is a non-crystalline $\mathrm{SiO}_{2}$ substrate, comparable with the top layer of the $\mathrm{SiO}_{2} / \mathrm{Si}$ substrate. Only after deposition of six layers, they could obtain a slightly oriented film on the quartz substrate. Taking into account that they found no interaction layer between the quartz substrate and the PT film, this might indicate the need for a multi-layered film in order to obtain some degree of crystallinity for the PT film.

Thermal treatment of the as deposited film on (0 01$) \mathrm{SrTiO}_{3}$ results for both $600^{\circ} \mathrm{C}$ and $700^{\circ} \mathrm{C}$ in a highly oriented film, Fig. 5(c) and (f). This epitaxial relationship has also been observed for other precursor systems and is attributed to the small lattice mismatch between $\mathrm{PT}$ and $\mathrm{SrTiO}_{3}{ }^{44,45}$ 

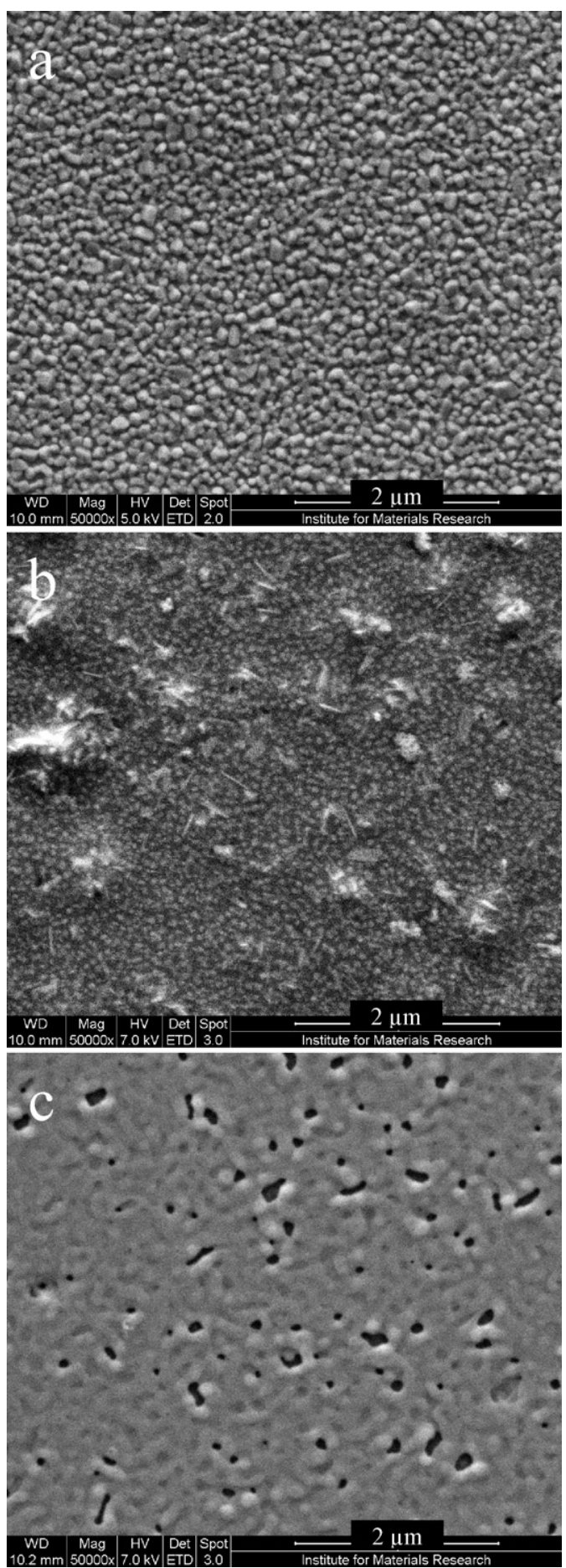

Fig. 4. Plane-view SE images obtained for the deposition of PT precursor solution A with a total metal ion concentration of $0.6 \mathrm{M}$ onto different substrates. The final crystallization temperature is $700{ }^{\circ} \mathrm{C}$. (a) $\mathrm{Pt}\left(\begin{array}{lll}1 & 1 & 1\end{array}\right) / \mathrm{IrO}_{2} / \mathrm{Ir} / \mathrm{SiO}_{2} / \mathrm{Si}$, (b) $\mathrm{SiO}_{2}(1.2 \mathrm{~nm}) / \mathrm{Si}$ and (c) (lo 01$) \mathrm{SrTiO}_{3}$.

\subsection{Effect of the crystallization temperature}

The aforementioned results clearly indicate that the formation of individual islands is most favourable on $\mathrm{Pt}\left(\begin{array}{lll}1 & 1 & 1\end{array}\right) / \mathrm{IrO}_{2} / \mathrm{Ir} / \mathrm{SiO}_{2} / \mathrm{Si}$ substrates and at a high temperature. To investigate the effect of the crystallization temperature on the formation of islands further and to check the stability of the substrate, a $0.6 \mathrm{M}$ PT precursor of solution A is spin coated on a platinized substrate, thermally treated and finally crystallized at different temperatures: $600^{\circ} \mathrm{C}, 700^{\circ} \mathrm{C}, 750{ }^{\circ} \mathrm{C}, 800^{\circ} \mathrm{C}, 850^{\circ} \mathrm{C}$ and $900^{\circ} \mathrm{C}$.

The obtained morphologies for the different crystallization temperatures are presented in Figs. 1 and 3(a). The small and numerous grains, formed at $700{ }^{\circ} \mathrm{C}$ (Fig. 1(a)) seem to grow together to form larger, but fewer grains at $750^{\circ} \mathrm{C}$ (Fig. 1(b)), with sizes between $100 \mathrm{~nm}$ and $190 \mathrm{~nm}$ and form even larger islands at $800{ }^{\circ} \mathrm{C}$ (Fig. 1(c) and (d)), where sizes between $120 \mathrm{~nm}$ and $205 \mathrm{~nm}$ are measured. Also, the intergrain distance becomes larger at elevated temperatures, there are more non-touching grains and the number of small grains is reduced. As the growing grains spheroidize and thereby uncover the substrate, it is believed that the grains grow by boundary motion to envelop the smaller grains. ${ }^{46}$

Crystallizing at even higher temperatures $\left(>800^{\circ} \mathrm{C}\right)$ disturbs the morphology, causes delamination of the platinum layer and destroys the substrate by promoting the crystal growth of $\mathrm{IrO}_{2}$ crystals through the top layer, as is observed in SEM images in Fig. 1(e) and (f). Qualitative EDX analysis shows that the formed crystals contain an elevated amount of Ir, which suggests that $\mathrm{IrO}_{2}$ is indeed present (EDX data not shown).

Increase of the crystallization temperature favours the formation of $(100)$ oriented PT grains, as can be seen in the $\mathrm{X}$-ray diffraction patterns for the different depositions on $\mathrm{Pt}\left(\begin{array}{lll}1 & 1 & 1\end{array}\right) / \mathrm{IrO}_{2} / \mathrm{Ir} / \mathrm{SiO}_{2} / \mathrm{Si}$ : Figs. 5(a) and (d) and 6(a). The inte-

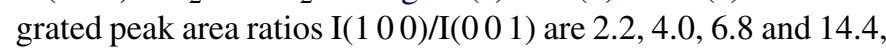
corresponding to the crystallization at $600{ }^{\circ} \mathrm{C}, 700^{\circ} \mathrm{C}, 750{ }^{\circ} \mathrm{C}$ (XRD not shown) and $800^{\circ} \mathrm{C}$, respectively.

At $900{ }^{\circ} \mathrm{C}$, no indication of a lead titanate phase can be found by X-ray diffraction, Fig. 6(b). Only diffractions owing to $\mathrm{IrO}_{2}$ (JCPDS 43-1019) and the substrate are present.

The literature reports different observations regarding the evolution of the $(100)$ orientation when increasing the crystallization temperature. Preferential (100) orientation has been observed by Lai et al. in a study of the influence of the anneal temperature on the film characteristics. ${ }^{47}$ They observed for an alcohol based sol-gel precursor, deposited on $\mathrm{Pt}\left(\begin{array}{ll}1 & 1\end{array}\right) / \mathrm{Ti} / \mathrm{Si}\left(\begin{array}{ll}0 & 0\end{array}\right)$, that an increase of the crystallization temperature from $450^{\circ} \mathrm{C}$ to $600^{\circ} \mathrm{C}$ resulted in a highly $(100)$ oriented film (thickness $0.15 \mu \mathrm{m}$ ). In our XRD patterns, we also observe an increase in $(100)$ orientation when increasing the anneal temperature.

A study conducted by Lu et al. ${ }^{48}$ on the other hand, showed that for the same substrate as Lai et al., $\operatorname{Pt}\left(\begin{array}{lll}1 & 1 & 1\end{array}\right) / \mathrm{Ti} / \mathrm{Si}\left(\begin{array}{ll}1 & 0\end{array}\right)$, an increase in temperature (from $620^{\circ} \mathrm{C}$ to $700^{\circ} \mathrm{C}$ ) resulted in less $(100)$ oriented $\mathrm{PbTiO}_{3}$ for a $0.28-\mu \mathrm{m}$ thick film. The inconsistency between both observations could be attributed to the film thicknesses, since for a $0.28-\mu \mathrm{m}$ thick film the driving force of the substrate towards a certain orientation is smaller than for a $0.15 \mu \mathrm{m}$ layer. Since we deposited a single layer, the obtained films have a strong $\left(\begin{array}{lll}1 & 0 & 0\end{array}\right)$ orientation, comparable with the results of Lai et al. As can be seen, a small change in the process conditions (layer thickness, anneal temperature) can lead to different results. 

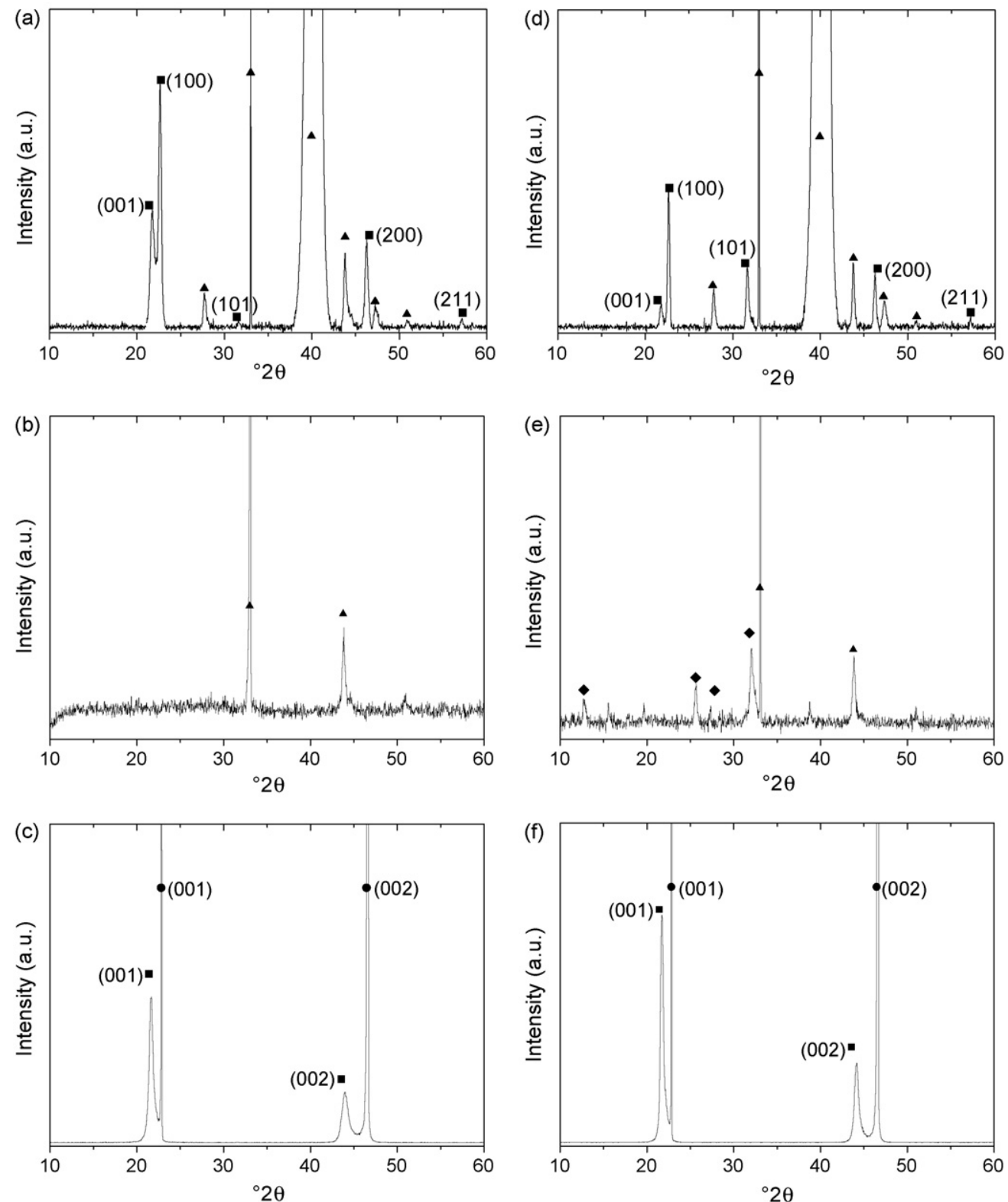

Fig. 5. X-ray diffraction patterns obtained for the depositions on different substrates. Left column (a), (b), and (c), crystallized at $600{ }^{\circ} \mathrm{C}$ and right column (d), (e),

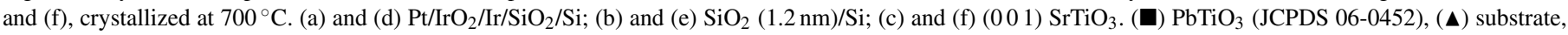
(ヤ) $\mathrm{Pb}_{2} \mathrm{O}_{3}$ (36-0725), (•) $\mathrm{SrTiO}_{3}(84-0444)$.
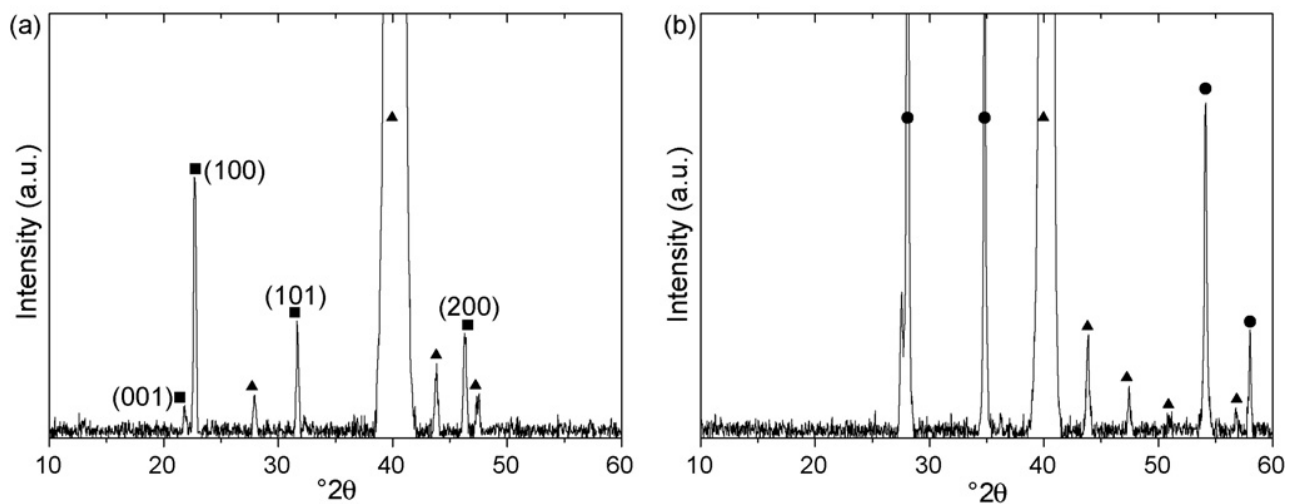

Fig. 6. X-ray diffraction patterns obtained for the deposition on $\mathrm{Pt} / \mathrm{IrO}_{2} / \mathrm{Ir} / \mathrm{SiO}_{2} / \mathrm{Si}$ and crystallization at different temperatures. (a) $800{ }^{\circ} \mathrm{C}$ and (b) $900{ }^{\circ} \mathrm{C}$. $\mathrm{PbTiO}_{3}$ (JCPDS 06-0452), (ム) substrate, (๑) $\mathrm{IrO}_{2}$ (43-1019). 
(a)

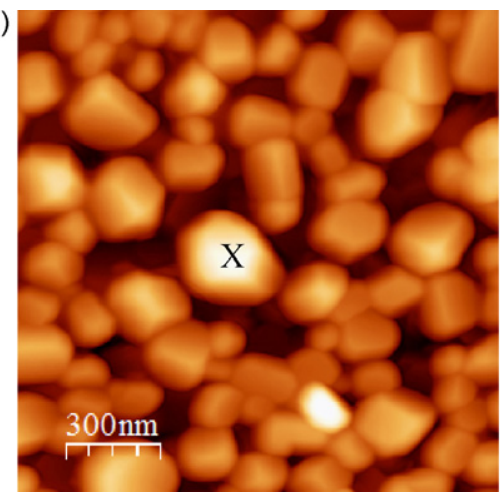

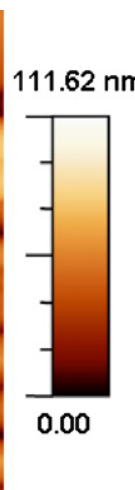

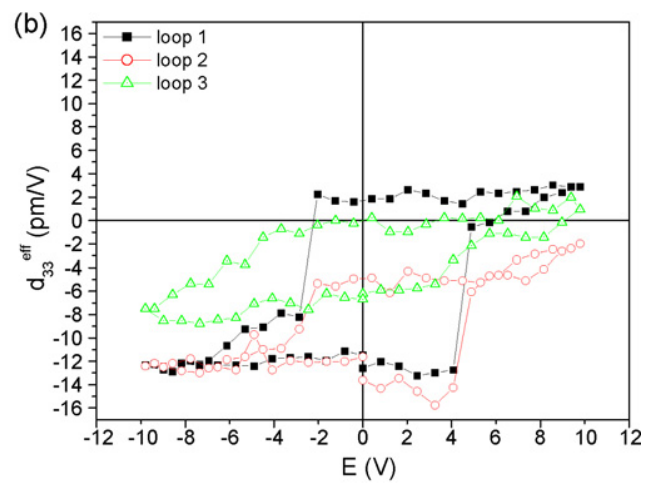

Fig. 7. Left a: topography image obtained by scanning force microscopy (SFM) of the deposited PT grains on the platinum substrate after crystallization at $750{ }^{\circ} \mathrm{C}$. Right b: local $d_{33}^{\text {eff }}$ hysteresis loop of the marked $(\times)$ grain on the SFM image.

Because of the well separated, small grains of pure PT islands, the crystallization temperature of $750^{\circ} \mathrm{C}$ leads to the desired results in terms of morphology and crystallographic phase. To prove the ferroelectric properties of the islands, local polarization loops are measured by means of PFM.

Fig. 7(a) shows a topography image obtained by scanning force microscopy (SFM) for the film crystallized at $750{ }^{\circ} \mathrm{C}$ together with three measured $d_{33}^{\text {eff }}$ loops, corresponding to the marked grain, Fig. 7(b). These loops indicate that the spontaneous polarization can be switched, demonstrating the presence of piezoelectric activity, and thus proving the ferroelectric character of the grains.

\subsection{Effect of the concentration}

To investigate the effect of dilution on the films' morphology, solutions of system B with a total metal ion concentration of $0.6 \mathrm{M}, 0.3 \mathrm{M}, 0.12 \mathrm{M}, 0.06 \mathrm{M}$ and $0.03 \mathrm{M}$ are deposited on the platinum substrate and crystallized at $700{ }^{\circ} \mathrm{C}$ for $30 \mathrm{~min}$.

Dilution of the precursor has an influence on morphology, grain size and intergrain distance, as was also reported for another precursor system where an alcohol was used as the solvent. ${ }^{49}$ This can also be observed in the SEM images shown in Fig. 2. Decrease of the concentration results in smaller grains, which lie further apart, as shown in Fig. 2(b) for a total metal ion concentration of $0.3 \mathrm{M}$. Grain sizes between $65 \mathrm{~nm}$ and $100 \mathrm{~nm}$ in diameter are observed. Further decrease of the concentration results in platelet-like and needle-like structures, as is clear for $0.12 \mathrm{M}$, Fig. 2(c). All lower concentrations ( $0.06 \mathrm{M}$ and $0.03 \mathrm{M})$ do not lead to distinguishable structures, no needles or grains are observed on the substrate, Fig. 2(d).

\section{Conclusions}

The obtained results show that starting from a water-based citrato(peroxo)-PT precursor solution, individual PT grains can be obtained if suitable experimental conditions are applied. Separated islands are obtained with sizes in the range of 50-200 nm.

Out of three different substrates it is found that

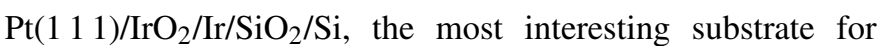
industrial applications, is also the most suitable candidate towards island formation if a $0.6 \mathrm{M}$ aqueous precursor solution is deposited. Increasing the crystallization temperature from $600^{\circ} \mathrm{C}$ to $800^{\circ} \mathrm{C}$ results in larger but more distant grains. Diluting the precursor results in smaller grains, but is limited to a total metal concentration of $0.3 \mathrm{M}$, since lower dilutions do not form separated grains but result in plate-like and needle-like structures.

Depositions on $\mathrm{SiO}_{2} / \mathrm{Si}$ and $\mathrm{SrTiO}_{3}$ do not result in separated grains for the $0.6 \mathrm{M}$ concentration. Instead, the deposition on silicon dioxide results in a continuous coverage of the substrate without the formation of a crystalline PT phase, whereas $\left(\begin{array}{lll}0 & 0 & 1\end{array}\right)$ $\mathrm{SrTiO}_{3}$ as a substrate results in a continuous but porous coverage of lead titanate with an epitaxial relationship with the substrate.

In general, it is shown that the films' morphology is mainly driven by the substrate and the concentration of the deposited solution. The sizes of the obtained islands are determined by the final crystallization temperature.

\section{Acknowledgements}

C. De Dobbelaere is a research assistant and M.K. Van Bael and A. Hardy are post-doctoral research fellows of the Research Foundation-Flanders (FWO Vlaanderen).

The authors would like to thank Dr. J. Ricote and Dr. M. L. Calzada of the Instituto de Ciencia de Materiales de Madrid (CSIC, Spain) for performing the PFM measurements. The authors acknowledge COST Action 539 ELENA.

\section{References}

1. Udomporn, A., Pengpat, K. and Ananta, S., Highly dense lead titanate ceramics from refined processing. J. Eur. Ceram. Soc., 2004, 24(2), 185-188.

2. Lee, M. H. and Choi, B. C., Crystallization of lead titanate prepared by wet chemical methods. J. Am. Ceram. Soc., 1991, 74(9), 2309-2311.

3. Camargo, E. R. and Kakihana, M., Peroxide-based route free from halides for the synthesis of lead titanate powder. Chem. Mater., 2001, 13(4), 1181-1184.

4. Xu, Y., Ferroelectric materials and their applications. Wiley, New York, 1990.

5. Chang, C. C. and Lin, W. J., Study and fabrication of the $\mathrm{PbTiO}_{3}$ thin film acoustic sensors. Ultrasonics, 2000, 37(8), 585-588.

6. Scott, J. F., Applications of modern ferroelectrics. Science, 2007, 315(5814), 954-959.

7. Polla, D. L., Ye, C. P. and Tamagawa, T., Surface-micromachined $\mathrm{PbTiO}_{3}$ pyroelectric detectors. Appl. Phys. Lett., 1991, 59(27), 3539-3541. 
8. Khan, M. A., Comyn, T. P. and Bell, A. J., Deposition of $\mathrm{PbTiO}_{3}$ films on $\mathrm{Pt} / \mathrm{Si}$ substrates using pulsed laser deposition. J. Eur. Ceram. Soc., 2008, 28(3), 591-597.

9. Theis, C. D. and Schlom, D. G., Epitaxial lead titanate grown by MBE. $J$. Crystal Growth, 1997, 174(1-4), 473-479.

10. Remiens, D., Tirlet, J. F., Jaber, B., Joire, H., Thierry, B. and Moriamez, C., Single-target sputter-deposition and post-processing of perovskite lead titanate thin-films. J. Eur. Ceram. Soc., 1994, 13(6), 493-500.

11. Madsen, L. D., Weaver, L. and Clark, A. J., The properties of lead titanate thin films produced by chemical vapour deposition. Can. J. Phys., 1996, 74(9-10), 580-593.

12. Nishida, K., Sugino, T., Osada, M., Kakihana, M. and Katoda, T., An orientation ratio and ferroelectric properties of ultra-thin PTO films. Appl. Surf. Sci., 2003, 216(1-4), 312-317.

13. Thomas, R. and Dube, D. C., Structural, electrical and optical properties of sol-gel processed lead titanate thin films. Jpn. J. Appl. Phys. Part 1: Regular Papers Short Notes Rev. Papers, 1997, 36(12A), 7337-7343.

14. Fujisawa, H., Okaniwa, M., Nonomura, H., Shimizu, M. and Niu, H., Ferroelectricity of the $1.7 \mathrm{~nm}$-high and $38 \mathrm{~nm}$-wide self-assembled $\mathrm{PbTiO}_{3}$ island. J. Eur. Ceram. Soc., 2004, 24(6), 1641-1645.

15. Schwartz, R. W., Schneller, T. and Waser, R., Chemical solution deposition of electronic oxide films. C. R. Chim., 2004, 7(5), 433-461.

16. Waser, R. and Rudiger, A., Ferroelectrics—pushing towards the digital storage limit. Nat. Mater., 2004, 3(2), 81-82.

17. Trolier-McKinstry, S., Piezoelectric films for MEMS applications. J. Ceram. Soc. Jpn., 2001, 109(5), S76-S79.

18. Alexe, M., Harnagea, C. and Hesse, D., Non-conventional micro- and nanopatterning techniques for electroceramics. J. Electroceram., 2004, 12(1-2), 69-88.

19. Lee, W., Han, H., Lotnyk, A., Schubert, M. A., Senz, S., Alexe, M. et al., Individually addressable epitaxial ferroelectric nanocapacitor arrays with near Tb inch(-2) density. Nat. Nanotechnol., 2008, 3(7), 402-407.

20. Szafraniak, I., Bhattacharyya, S., Harnagea, C., Scholz, R. and Alexe, M., Self-assembled ferroelectric nanostructures. Integr. Ferroelectr., 2004, 68 , 279-286.

21. Calzada, M. L., Torres, M., Fuentes-Cobas, L. E., Mehta, A., Ricote, J. and Pardo, L., Ferroelectric self-assembled $\mathrm{PbTiO}_{3}$ perovskite nanostructures onto $(100) \mathrm{SrTiO}_{3}$ substrates from a novel microemulsion aided sol-gel preparation method. Nanotechnology, 2007, 18(37), 375603.

22. Kronholz, S., Rathgeber, S., Karthäuser, S., Kohlstedt, H., Clemens, S. and Schneller, T., Self-assembly of diblock-copolymer micelles for templatebased preparation of $\mathrm{PbTiO}_{3}$ nanograins. Adv. Funct. Mater, 2006, 16(18), 2346-2354.

23. Clemens, S., Schneller, T., van der Hart, A., Peter, F. and Waser, R., Registered deposition of nanoscale ferroelectric grains by template-controlled growth. Adv. Mater., 2005, 17(11), 1357-1361.

24. Truijen, I., Van Bael, M. K., Van den Rul, H., D’Haen, J. and Mullens, J., Preparation of nanocrystalline titania films with different porosity by waterbased chemical solution deposition. J. Sol-Gel Sci. Technol., 2007, 43(3), 291-297.

25. Bretos, I., Jimenez, R., Calzada, M. L., Van Bael, M. K., Hardy, A., Van Genechten, D. et al., Entirely aqueous solution-gel route for the preparation of $\left(\mathrm{Pb}_{1-\mathrm{x}} \mathrm{Ca}_{\mathrm{x}}\right) \mathrm{TiO}_{3}$ thin films. Chem. Mater, 2006, 18(26), 6448-6456.

26. Pagnaer, J., Nelis, D., Mondelaers, D., Vanhoyland, G., D'Haen, J., Van Bael, M. K. et al., Synthesis of $\mathrm{RuO}_{2}$ and $\mathrm{SrRuO}_{3}$ powders by means of aqueous solution gel chemistry. J. Eur. Ceram. Soc., 2004, 24(6), 919-923.

27. Nelis, D., Van Werde, K., Mondelaers, D., Vanhoyland, G., Van den Rul, H. Van Bael, M. K. et al., Aqueous solution-gel synthesis of strontium bismuth niobate $\left(\mathrm{SrBi}_{2} \mathrm{Nb}_{2} \mathrm{O}_{9}\right)$. J. Sol-Gel Sci. Technol., 2003, 26(1-3), 1125-1129.

28. Van den Rul, H., Mondelaers, D., Van Bael, M. K. and Mullens, J., Waterbased wet chemical synthesis of (doped) $\mathrm{ZnO}$ nanostructures. J. Sol-Gel Sci. Technol., 2006, 39(1), 41-47.

29. Hardy, A., D’Haen, J., Goux, L., Wouters, D., Van Bael, M. K., Van den Rul, H. et al., Aqueous chemical solution deposition of ferroelectric $\mathrm{Ti}^{4+}$ cosubstituted $(\mathrm{Bi}, \mathrm{La})(4) \mathrm{Ti}_{3} \mathrm{O}_{12}$ thin films. Chem. Mater., 2007, 19(12), 2994-3001.
30. Hardy, A., Van Elshocht, S., D’Haen, J., Douheret, O., De Gendt, S., Adelmann, C. et al., Aqueous chemical solution deposition of ultrathin lanthanide oxide dielectric films. J. Mater. Res., 2007, 22(12), 3484-3493.

31. Cho, W. S. and Yoshimura, M., Hydrothermal synthesis of $\mathrm{PbTiO}_{3}$ films. $J$. Mater. Res., 1997, 12(3), 833-839.

32. Alemany, C., Jimenez, R., Revilla, J., Mendiola, J. and Calzada, M. L., Pulsed hysteresis loops on ferroelectric thin films. J. Phys. D: Appl. Phys., 1999, 32(17), L79-L82.

33. Van Werde, K., Vanhoyland, G., Nelis, D., Mondelaers, D., Van Bael, M. K., Mullens, J. et al., Phase formation of ferroelectric perovskite 0.75 $\mathrm{Pb}\left(\mathrm{Zn}_{1 / 3}, \mathrm{Nb}_{2 / 3}\right) \mathrm{O}_{3}-0.25 \mathrm{BaTiO}_{3}$ prepared by aqueous solution-gel chemistry. J. Mater. Chem., 2001, 11(4), 1192-1197.

34. Hardy, A., D'Haen, J., Van Bael, M. K. and Mullens, J., An aqueous solution-gel citratoperoxo-Ti(IV) precursor: synthesis, gelation, thermooxidative decomposition and oxide crystallization. J. Sol-Gel Sci. Technol., 2007, 44(1), 65-74.

35. Nouwen, R., Mullens, J., Franco, D., Yperman, J. and Van Poucke, L. C., Use of thermogravimetric analysis Fourier transform infrared spectroscopy in the study of the reaction mechanism of the preparation of $\mathrm{Pb}(\mathrm{Zr}, \mathrm{Ti}) \mathrm{O}_{3}$ by the sol-gel method. Vibrational Spectrosc., 1996, 10(2), 291299.

36. Van Werde, K., Vanhoyland, G., Mondelaers, D., Van den Rul, H., Van Bael, M. K., Mullens, J. et al., The aqueous solution-gel synthesis of perovskite $\mathrm{Pb}\left(\mathrm{Zr}_{1-\mathrm{x}}, \mathrm{Ti}_{\mathrm{x}}\right) \mathrm{O}_{3}$ (PZT). J. Mater. Sci., 2007, 42(2), 624-632.

37. Van Bael, M. K., Nelis, D., Hardy, A., Mondelaers, D., Van Werde, K., D'Haen, J. et al., Aqueous chemical solution deposition of ferroelectric thin films. Integr. Ferroelectr., 2002, 45, 113-122.

38. Nelis, D., Van Werde, K., Mondelaers, D., Vanhoyland, G., Van Bael, M. K., Mullens, J. et al., Synthesis of $\mathrm{SrBi}_{2} \mathrm{Ta}_{2} \mathrm{O}_{9}$ (SBT) by means of a soluble $\mathrm{Ta}(\mathrm{V})$ precursor. J. Eur. Ceram. Soc., 2001, 21(10-11), 2047-2049.

39. Deng, Y. F., Jiang, Y. Q., Hong, Q. M. and Zhou, Z. H., Speciation of watersoluble titanium citrate: synthesis, structural, spectroscopic properties and biological relevance. Polyhedron, 2007, 26(8), 1561-1569.

40. Malic, B., Kosec, M., Smolej, K. and Stavber, S., Effect of precursor type on the microstructure of $\mathrm{PbTiO}_{3}$ thin films. J. Eur. Ceram. Soc., 1999, 19(6-7), $1345-1348$

41. Mühlebach, J., Müller, K. and Schwarzenbach, G., Peroxo complexes of titanium. Inorg. Chem., 1970, 9(11), 2381-2390.

42. Dakanali, M., Kefalas, E. T., Raptopoulou, C. P., Terzis, A., Voyiatzis, G., Kyrikou, I. et al., A new dinuclear Ti(IV)-peroxo-citrate complex from aqueous solutions. Synthetic, structural, and spectroscopic studies in relevance to aqueous titanium(IV)-peroxo-citrate speciation. Inorg. Chem., 2003, 42(15), 4632-4639.

43. Truijen, I., Hardy, A., Van Bael, M. K., Van den Rul, H. and Mullens, J., Study of the decomposition of aqueous citratoperoxo-Ti(IV)-gel precursors for titania by means of TGA-MS and FTIR. Thermochim. Acta, 2007, 456(1), $38-47$.

44. Kushida, K., Udayakumar, K. R., Krupanidhi, S. B. and Cross, L. E., Origin of orientation in sol-gel-derived lead titanate films. J. Am. Ceram. Soc., 1993, 76(5), 1345-1348.

45. Szafraniak, I., Harnagea, C., Scholz, R., Bhattacharyya, S., Hesse, D. and Alexe, M., Ferroelectric epitaxial nanocrystals obtained by a self-patterning method. Appl. Phys. Lett., 2003, 83(11), 2211-2213.

46. Miller, K. T., Lange, F. F. and Marshall, D. B., The instability of polycrystalline thin-films-experiment and theory. J. Mater. Res., 1990, 5(1), $151-160$.

47. Lai, Y. C., Lin, J. C. and Lee, C. P., Nucleation and growth of highly oriented lead titanate thin films prepared by a sol-gel method. Appl. Surf. Sci., 1998, 125(1), 51-57.

48. Lu, C. J., Shen, H. M., Liu, J. S. and Wang, Y. N., The oriented growth of $\mathrm{PbTiO}_{3}$ thin films deposited by a sol-gel process on substrates without lattice match. J. Phys. D: Appl. Phys., 1997, 30(16), 2338-2342.

49. Roelofs, A., Schneller, T., Szot, K. and Waser, R., Towards the limit of ferroelectric nanosized grains. Nanotechnology, 2003, 14(2), 250253. 